\title{
Extending the Comprehensiveness of Immunopeptidome Analyses Using Isobaric Peptide Labeling
}

Sibylle Pfammatter ${ }^{1,2}$, Eric Bonneil ${ }^{1}$, Joel Lanoix ${ }^{1}$, Krystel Vincent ${ }^{1}$, Marie-Pierre Hardy $^{1}$, Mathieu Courcelles ${ }^{1}$, Claude Perreault ${ }^{1,3^{*}}$ and Pierre Thibault ${ }^{1,2^{*}}$

${ }^{1}$ Institute for Research in Immunology and Cancer, ${ }^{2}$ Department of Chemistry, ${ }^{3}$ Department of Medicine, Université de Montréal, P.O. Box 6128, Station. Centreville, Montréal, Québec, Canada H3C 3J7

Correspondence : Pierre Thibault (pierre.thibault@umontreal.ca) or Claude Perreault (claude.perreault@umontreal.ca)

\begin{abstract}
Defining the repertoire of peptides presented by the major histocompatibility complex class I (MHC I) is a key step towards the identification of relevant antigens for cancer immunotherapy. However, the identification of cancer-specific antigens is a significant analytical challenge in view of their low abundance and low mutational load found in most primary cancer specimens. Here, we describe the application of isobaric peptide labeling with tandem mass tag (TMT) to improve the detection of the MHC I peptides. Isobaric peptide labeling was found to promote the formation of multiply-charged ions and to enhance the formation of b-type fragment ions, thus resulting in a $50 \%$ improvement of MHC I peptide identification. The gain in sensitivity obtained using TMT labeling enabled the detection of low abundance MHC I peptides including tumor-specific antigens (TSAs) and minor histocompatibility antigens (MiHAs). We further demonstrate the application of this approach to quantify MiHAs presented by B-cell lymphocytes and determined their expression levels by LC-MS/MS using both synchronous precursor selection (SPS) and high field asymmetric waveform ion mobility spectrometry (FAIMS).
\end{abstract}




\section{Table of content:}

Supplementary Table 1: Triplicate LC-MS/MS analyses of native and TMT-labeled MHC I peptides from 2 million B-LCL cells with different LC gradient lengths (90min, 180min and 240min). Provided as separate XLSX file.

Supplementary Table 2: Triplicate LC-MS/MS analyses of TMT-labeled MHC I peptides from 20, 60 and 100 million B-ALL cells and one replicate for native conditions. Provided as separate XLSX file.

Supplementary Table 3: Targeted LC-MS/MS analyses of TMT-labeled MiHAs. Provided as separate XLSX file.

\section{Supplementary methods}

Supplementary Figure 1: TMT labeling extend the immunopeptidome coverage of B-LCL cells.

Supplementary Figure 2: Comparison of MHC I peptide intensities obtained between different gradient elution conditions.

Supplementary Figure 3: Distribution of fragment ions for native and TMT-labeled MHC I peptides from B-LCL cells.

Supplementary Figure 4: Scalability of TMT labeling for different amounts of B-ALL cells.

Supplementary Figure 5: Tile chart showing the average RNA expression of peptide-coding sequences of aeTSAs from B-ALL cells.

Supplementary Figure 6: Mirror plots of all TMT-labeled aeTSA peptides and their synthetic counterparts 


\section{Supplementary information}

\section{Supplementary methods:}

\section{Immunoprecipitation of MHC I}

The W6/32 antibodies (BioXcell) were incubated in PBS for $60 \mathrm{~min}$ at room temperature with PureProteome protein A magnetic beads (Millipore) at a ratio of $1 \mathrm{mg}$ of antibody per mL of slurry. Antibodies were covalently cross-linked to magnetic beads using dimethylpimelidate as described previously ${ }^{11}$. The beads were stored at $4{ }^{\circ} \mathrm{C}$ in PBS pH 7.2 and $0.02 \% \mathrm{NaN}_{3}$. Biological replicates of cell pellets were resuspended in $1 \mathrm{~mL} \mathrm{PBS} \mathrm{pH} 7.2$ and solubilized by adding $1 \mathrm{~mL}$ of detergent buffer containing PBS pH 7.2, 1\% (w/v) CHAPS (Sigma) supplemented with Protease inhibitor cocktail (Sigma). After 60 min incubation with tumbling at $4^{\circ} \mathrm{C}$, samples were spun at $16,000 \mathrm{~g}$ for $30 \mathrm{~min}$ at $4^{\circ} \mathrm{C}$. Supernatants were transferred into new tubes containing magnetic beads coupled to $\mathrm{W} 6 / 32$ antibodies at a ratio of $10 \mu \mathrm{g}$ of $\mathrm{W} 6 / 32$ antibody per $1 \times 10^{6}$ cells. For the immunoprecipitation, aliquots of $1 \times 10^{8}$ cells were used and combined at the end. Samples were incubated with tumbling for $180 \mathrm{~min}$ at $4^{\circ} \mathrm{C}$ and placed on a magnet to recover bound $\mathrm{MHC}$ I complexes to magnetic beads. Magnetic beads were first washed with $8 \times 1 \mathrm{~mL}$ PBS, then with 1 $\times 1 \mathrm{~mL}$ of $0.1 \mathrm{X}$ PBS, and finally with $1 \times 1 \mathrm{~mL}$ of water. MHC I complexes were eluted from the magnetic beads by acidic treatment using $0.2 \%$ formic acid (FA). To remove any residual magnetic beads, eluates were transferred into $2 \mathrm{~mL}$ Costar $\mathrm{mL}$ Spin-X centrifuge tube filters $(0.45 \mu \mathrm{m}$, Corning) and spun $2 \mathrm{~min}$ at $855 \mathrm{~g}$. Filtrates containing peptides were separated from MHC I subunits (HLA molecules and $\beta$-2 macroglobulin) using home-made stage tips packed with twenty $1 \mathrm{~mm}$ diameter octadecyl (C-18) solid-phase extraction disks (EMPORE). Stage tips were prewashed first with methanol then with $80 \%$ acetonitrile $(\mathrm{ACN})$ in $0.1 \%$ trifluoroacetic acid (TFA) and finally with $0.1 \%$ formic acid (FA). Samples were loaded onto the stage tips and the peptides 


\section{Supplementary information}

were retained on the stage tips while the HLA molecules and $\beta-2$ macroglobulin were found in the flow through. Stage tips were washed with $0.1 \%$ FA and peptides were eluted with $30 \%$ ACN in $0.1 \% \mathrm{TFA}$. The peptides were dried using vacuum centrifugation and then stored at $-20^{\circ} \mathrm{C}$ until MS analysis.

\section{Mass spectrometry}

Vacuum dried peptides were resuspended $4 \%$ FA and analyzed by LC-MS/MS using an Easy nLC1000 coupled to a Tribrid Orbitrap Fusion mass spectrometer (Thermo Fisher Scientific). Peptides were separated on a custom C18 reversed-phase column (150 $\mu$ m i.d. x 200 mm, Jupiter Proteo $4 \mu \mathrm{m}, 300 \AA$, Phenomenex) using a flow rate of $600 \mathrm{~nL} / \mathrm{min}$ and a linear gradient of $5-40 \%$ ACN $(0.2 \% \mathrm{FA})$ in $150 \mathrm{~min}$, followed by $15 \mathrm{~min}$ at $70 \% \mathrm{ACN}(0.2 \% \mathrm{FA})$ and $15 \mathrm{~min}$ reequilibration at $5 \% \mathrm{ACN}(0.2 \% \mathrm{FA})$. Survey scan (MS1) were acquired with the Orbitrap at a resolving power of $120,000(\mathrm{at} \mathrm{m} / \mathrm{z} 200)$ over a scan range of $300-1100 \mathrm{~m} / \mathrm{z}$ with a target values of $5 \times 10^{5}$ with a maximum injection time of $100 \mathrm{~ms}$. MS/MS spectra were acquired at higher energy collisional dissociation with a normalized collision energy of 35 , and an exclusion time of 45s. Up to twenty precursor ions were accumulated with a precursor isolation window of $1.6 \mathrm{~m} / \mathrm{z}$, an advanced gain control (AGC) of $2 \times 10^{4}$ with a maximum injection time of $500 \mathrm{~ms}$ and fragment ions were transferred to the Orbitrap analyzer operating at a resolution of 50,000 at $\mathrm{m} / \mathrm{z} 200$. For the TMT 10-plex analysis with FAIMS, the MS2 approach described above was used with minor modifications. The linear gradient was shortened to $60 \mathrm{~min}$, followed by $15 \mathrm{~min}$ re-equilibration at $5 \% \mathrm{ACN}(0.2 \% \mathrm{FA})$, and targeted LC-MS/MS used a list of selected precursor ions. The MS1 maximum injection time was set to $50 \mathrm{~ms}$, and the isolation window for MS2 was 1 Th with an offset of 0.3 Th. For the SPS-MS3 method, the parameters for the MS scan were the same as for the FAIMS MS2 method (scan range m/z 300-1,100, Orbitrap resolution 120,000, AGC 5x10 5 and 
maximum injection time $50 \mathrm{~ms}$ ) followed by a $3 \mathrm{sec}$ top speed approach for MS2 in the ion trap (Isolation window $0.7 \mathrm{Th}, \mathrm{CID}$ at $35 \%$ collision energy, normal scan rate mode, AGC $2 \times 10^{4}$ with maximal injection time of $50 \mathrm{~ms}$ ) followed by the selection of synchronous precursor ions for MS3 acquisition (scan range $\mathrm{m} / \mathrm{z} 100-500$, Orbitrap resolution of 50,000 , AGC of $1 \times 10^{5}$, maximum injection time of $300 \mathrm{~ms}, 4$ notches, isolation window of $2.0 \mathrm{Th}$ and a collision energy of up to 65 $\%)$. 
Supplementary information

a

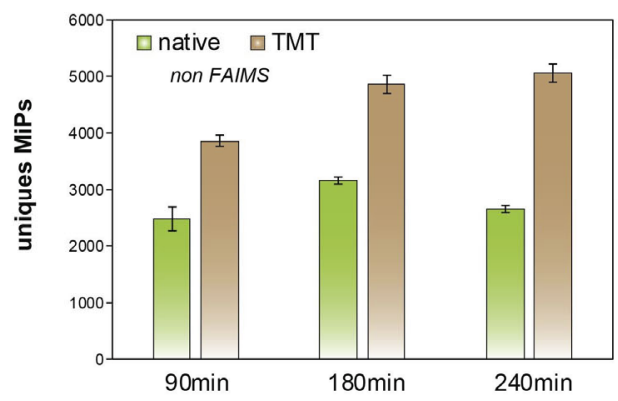

b
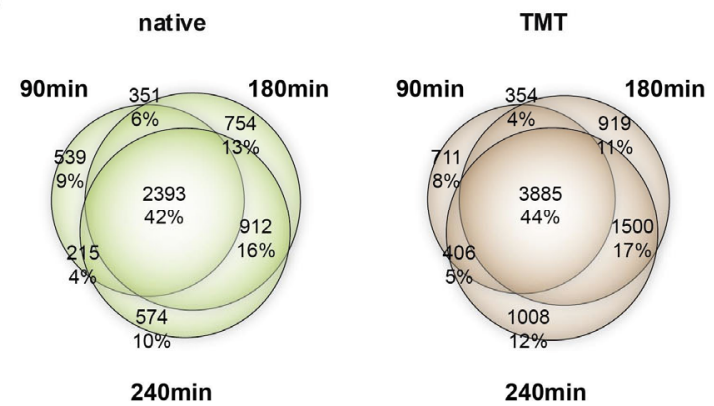

$240 \mathrm{~min}$

C
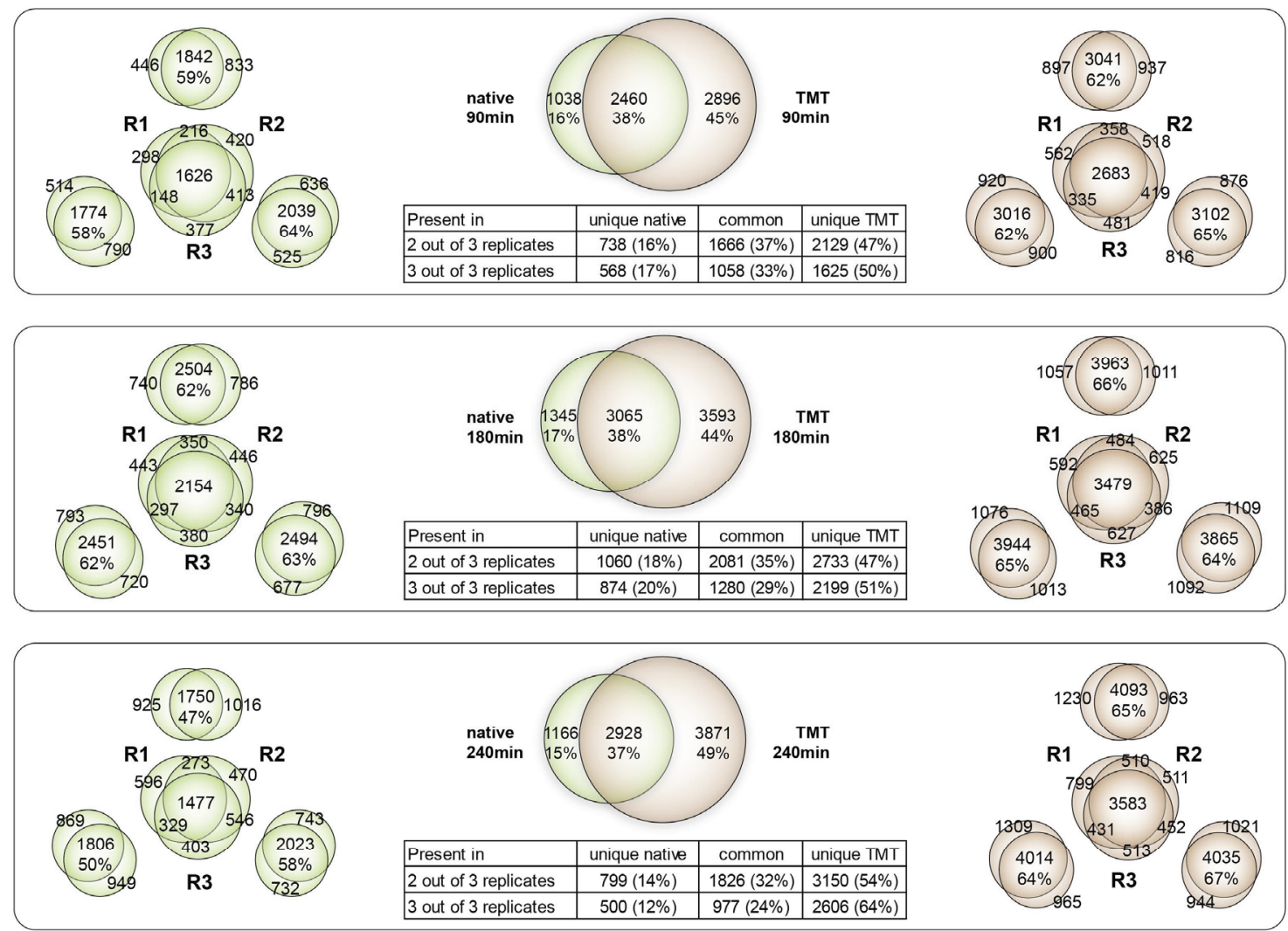

Supplementary Figure 1: TMT labeling extend the immunopeptidome coverage of B-LCL cells. a) Comparison of the number of native and TMT-labeled MHC I peptides identified under different gradient elution conditions for the equivalent of $2 \times 10^{6} \mathrm{~B}-\mathrm{LCL}$ cells. b) Venn diagrams showing the overlap of identified $\mathrm{MHC}$ I peptides for different gradient elution conditions. c) Overlap in the number of identification for native and TMT-labeled MHC I peptides across replicate injections. 
Supplementary information

a

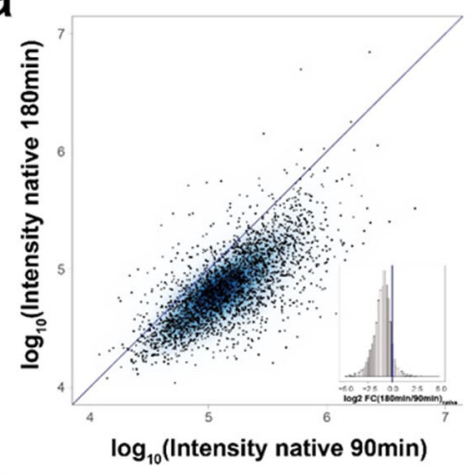

d

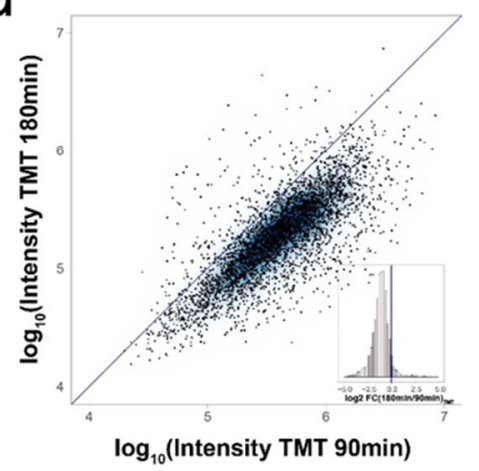

b

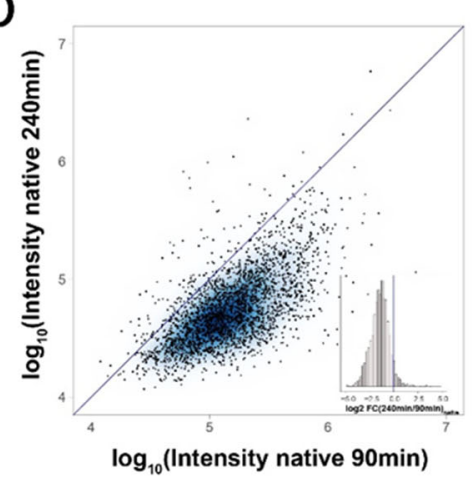

e

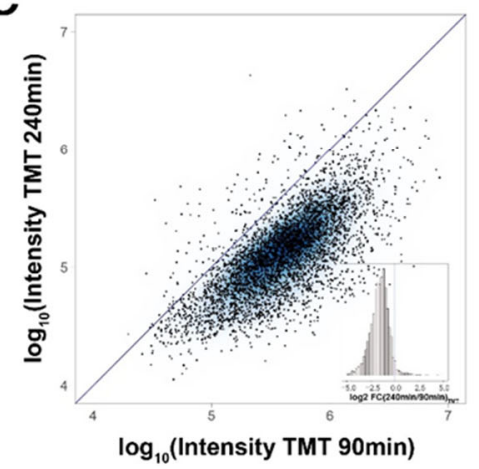

C

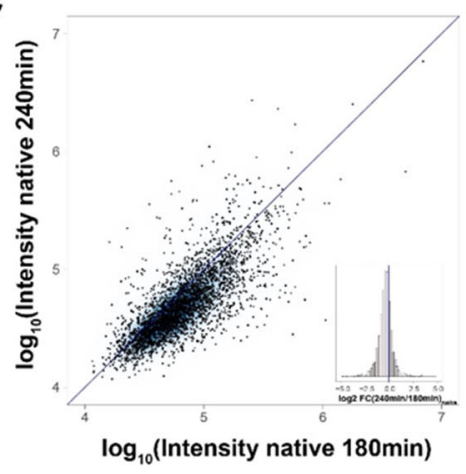

f

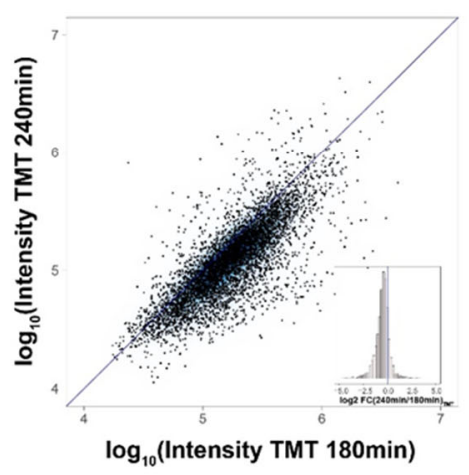

Supplementary Figure 2: Comparison of $\mathrm{MHC}$ I peptide intensities obtained between different gradient elution conditions. Native MHC I peptides intensities at a) 90 and $180 \mathrm{~min} \mathrm{b)} 90$ and $240 \mathrm{~min}$ and c) 180 and 240 min gradient elution. TMT-labeled MHC I peptides intensities at d) 90 and $180 \mathrm{~min}$ e) 90 and $240 \mathrm{~min}$ and f) 180 and 240 min gradient elution. 


\section{Supplementary information}

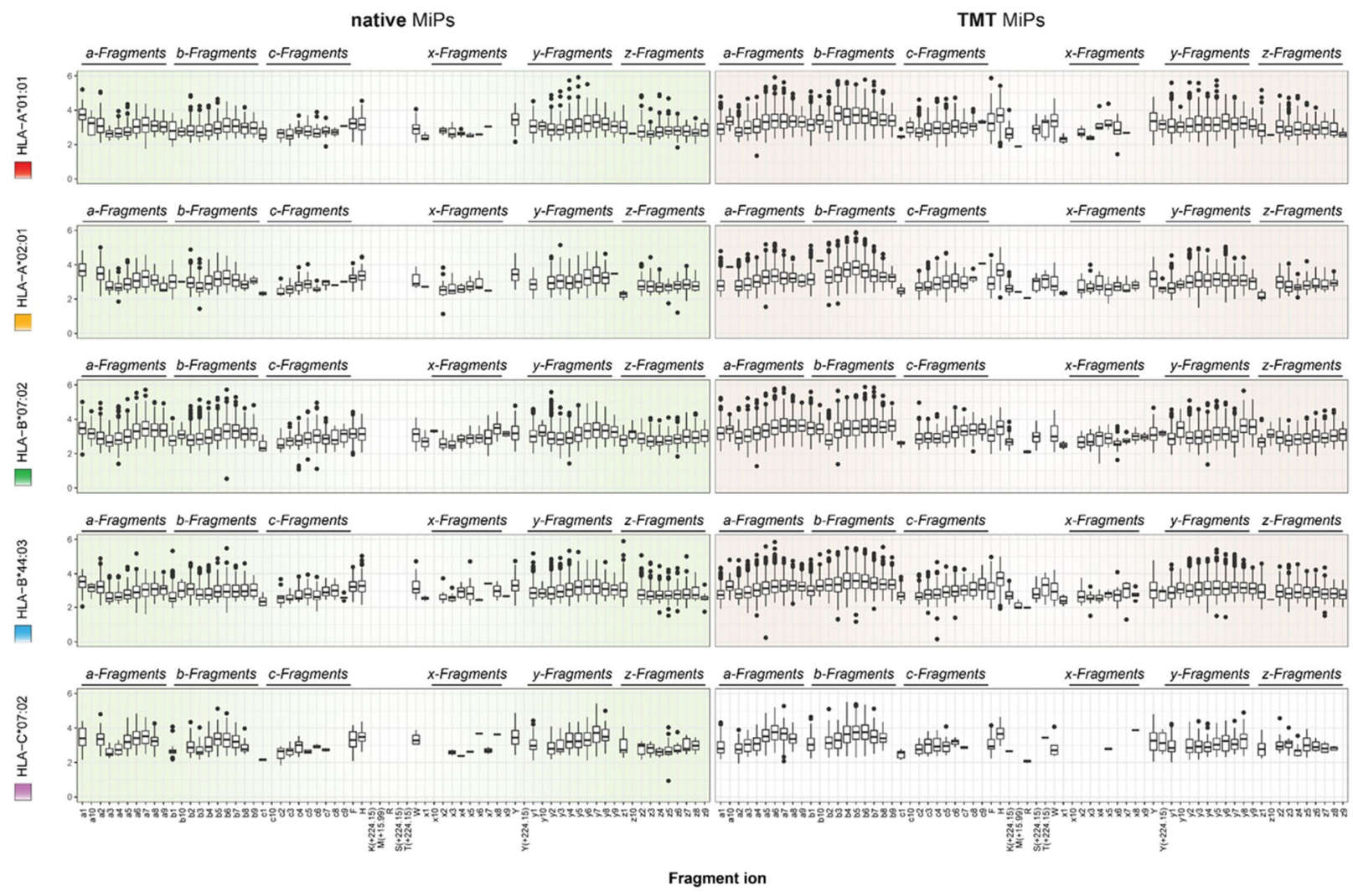

Supplementary Figure 3: Distribution of fragment ions for native and TMT-labeled MHC I peptides from B-LCL cells. 


\section{TMT}

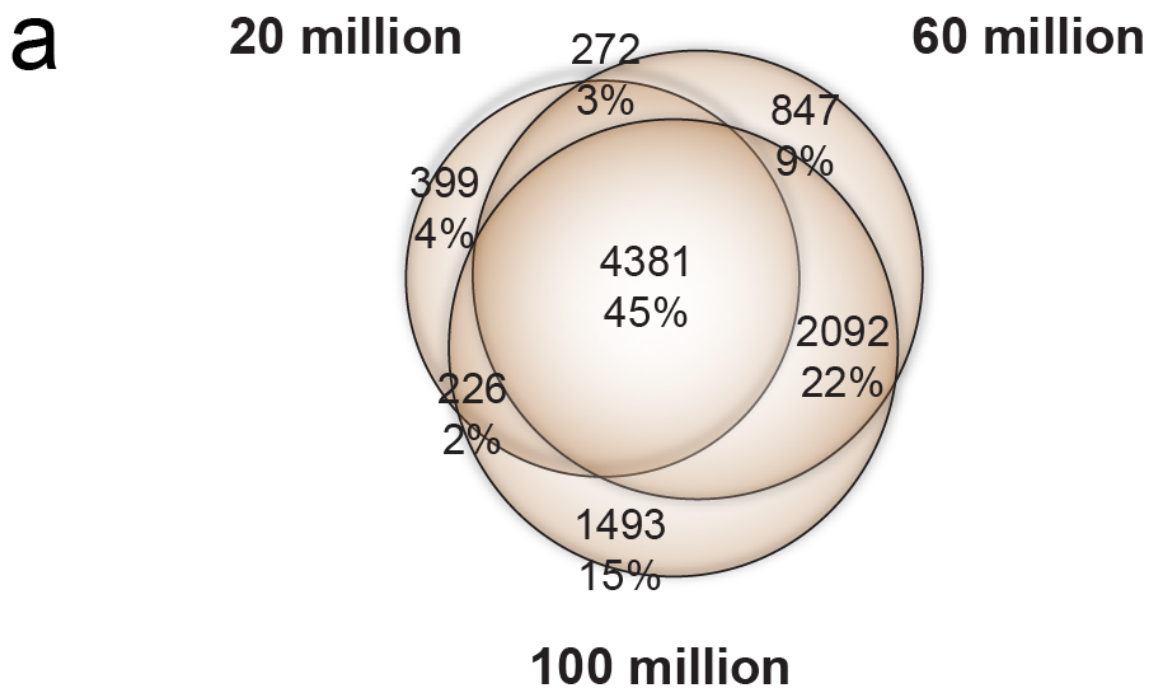

b

TMT

20 million
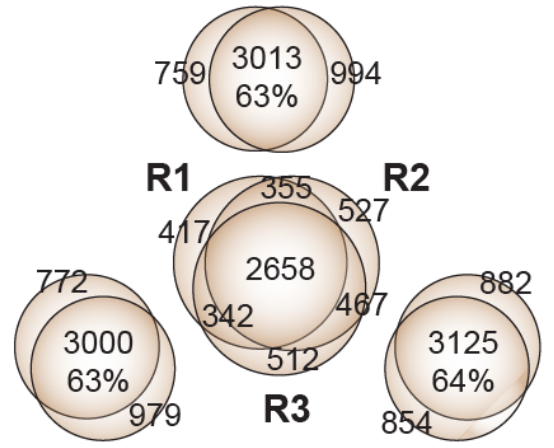

TMT 60 million
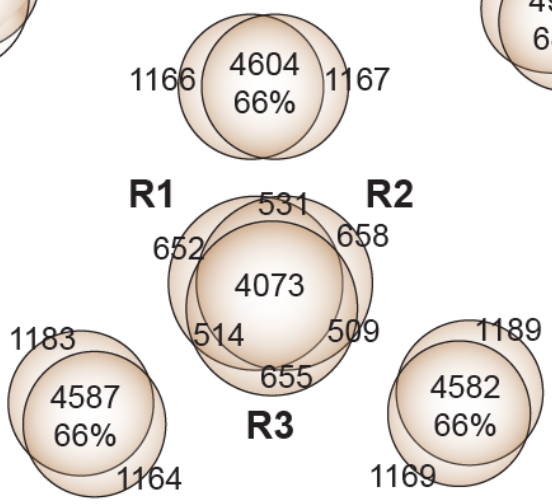

TMT 100 million

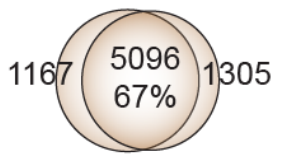

R1<smiles>[R10]C=CC=[V]</smiles>

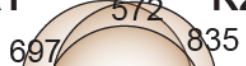

4524

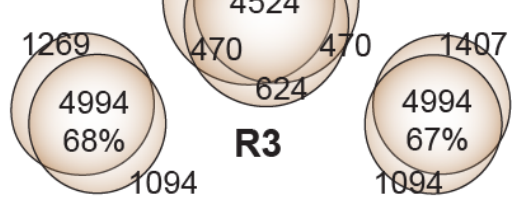

Supplementary Figure 4: Scalability of TMT labeling for different amounts of B-ALL cells. a) Venn diagram showing the number of identified MHC I peptides for 20, 60 and 100 million BALL cells (triplicate injection). b) Overlap of peptide identification across triplicate injection. 
Supplementary information

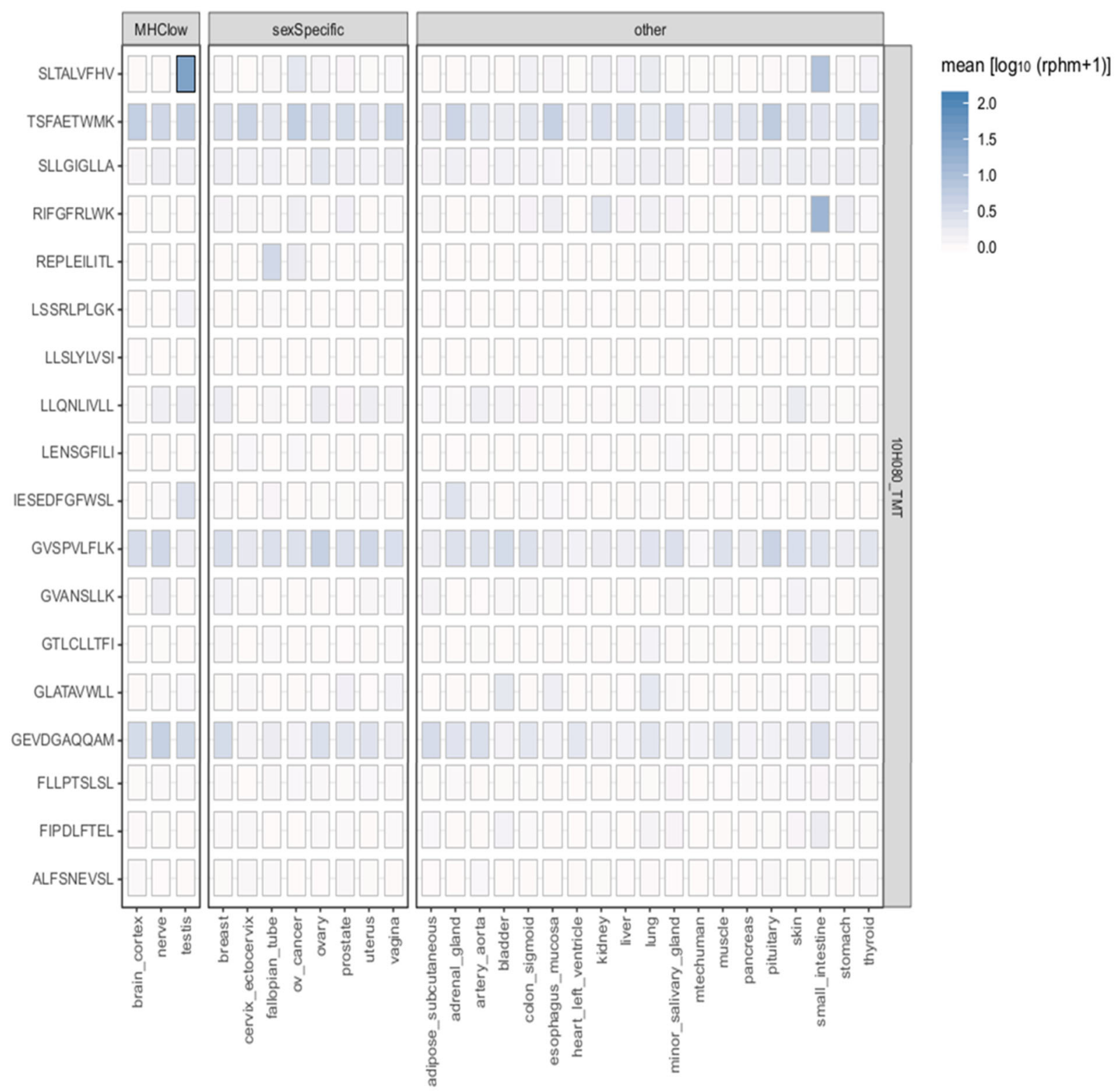

Supplementary Figure 5: Tile chart showing the average RNA expression of peptide-coding sequences of aeTSAs from B-ALL cells (10H080), in reads per hundred million reads sequenced (rphm), across a panel of 30 normal adult tissues RNA sequencing data ( $\sim 50$ donors per tissue), which have been sequenced by the GTEx consortium and downloaded from the GTEx Portal. Rphm values were calculated as described by Laumont C. et al, 2018 [Laumont et al., Sc. Transl. Med, 10 (470), 2018]. 
Supplementary Figure 6: Mirror plots of all TMT-labeled aeTSA peptides and their synthetic counterparts

ALFSNEVSL / $2+$

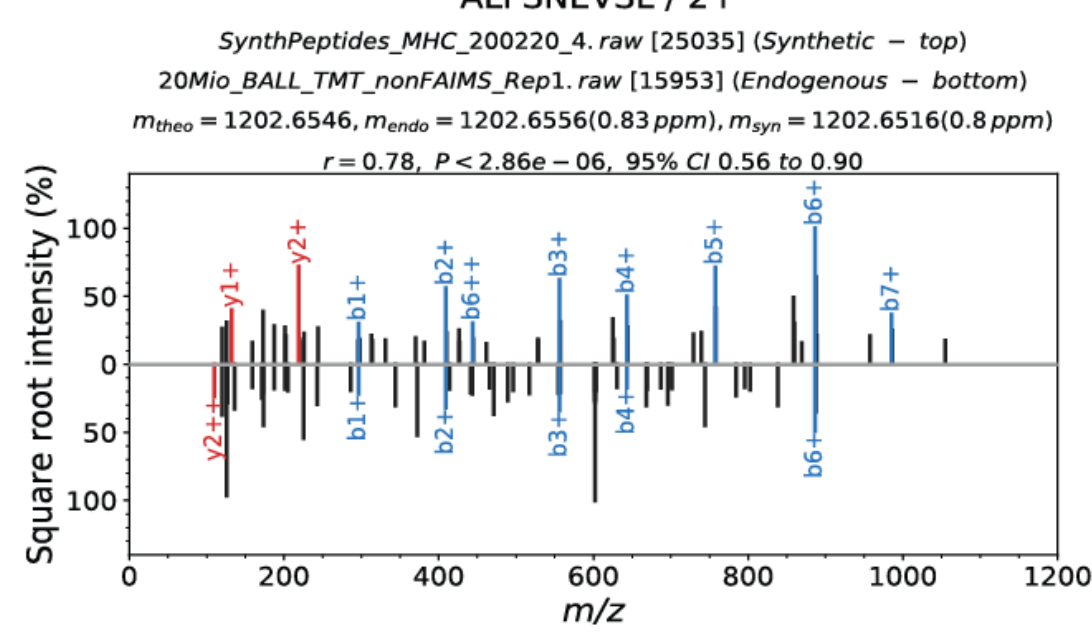

Rt $=96.3$

$\mathrm{Rt}=96.1$

FIPDLFTEL / $2+$

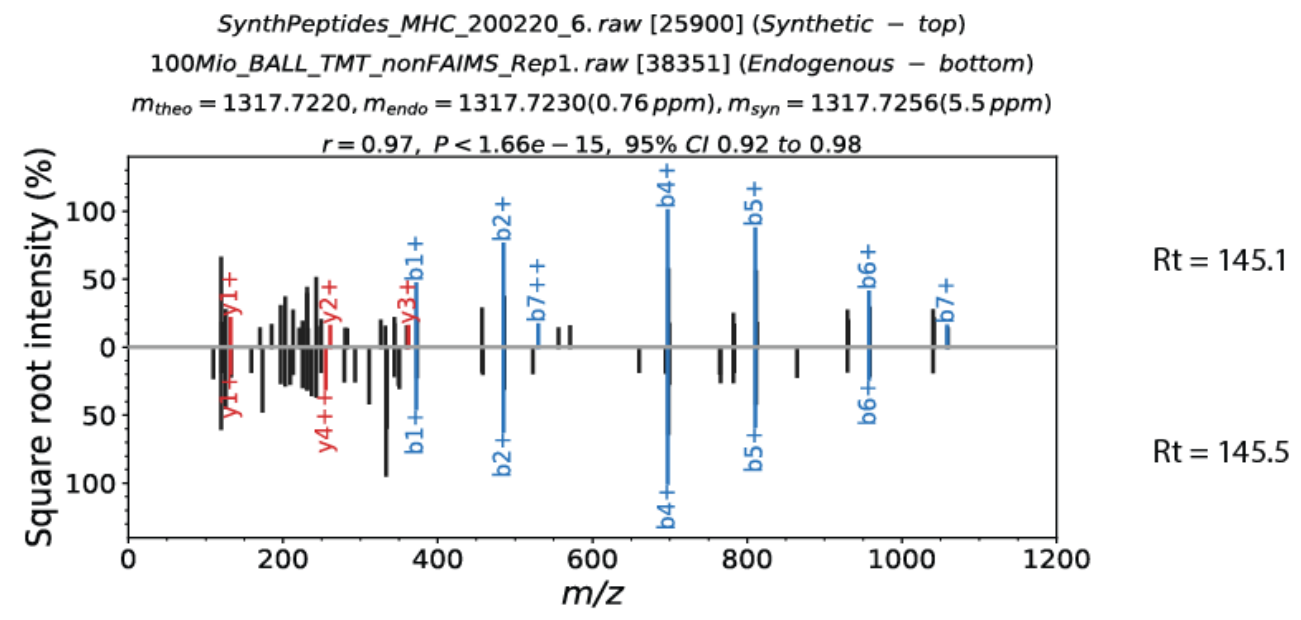

FLLPTSLSL / 2+

SynthPeptides_MHC_200220_6.raw [23003] (Synthetic - top) 100Mio_BALL_TMT_nonFAIMS_Rep2.raw [33678] (Endogenous - bottom) $m_{\text {theo }}=1213.7321, m_{\text {endo }}=1213.7308(-1.07 \mathrm{ppm}), m_{\text {syn }}=1213.7350(5.1 \mathrm{ppm})$

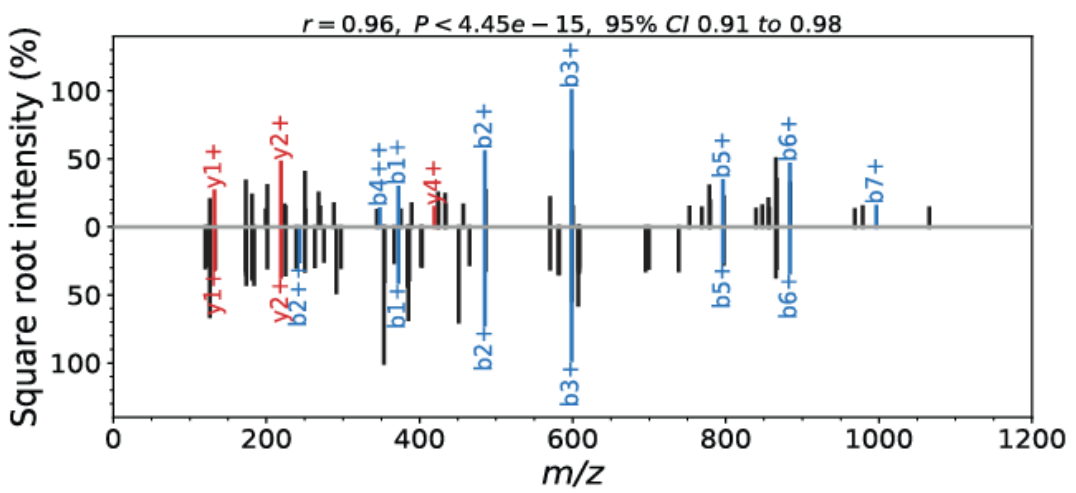

$\mathrm{Rt}=124.1$

$\mathrm{Rt}=124.5$ 


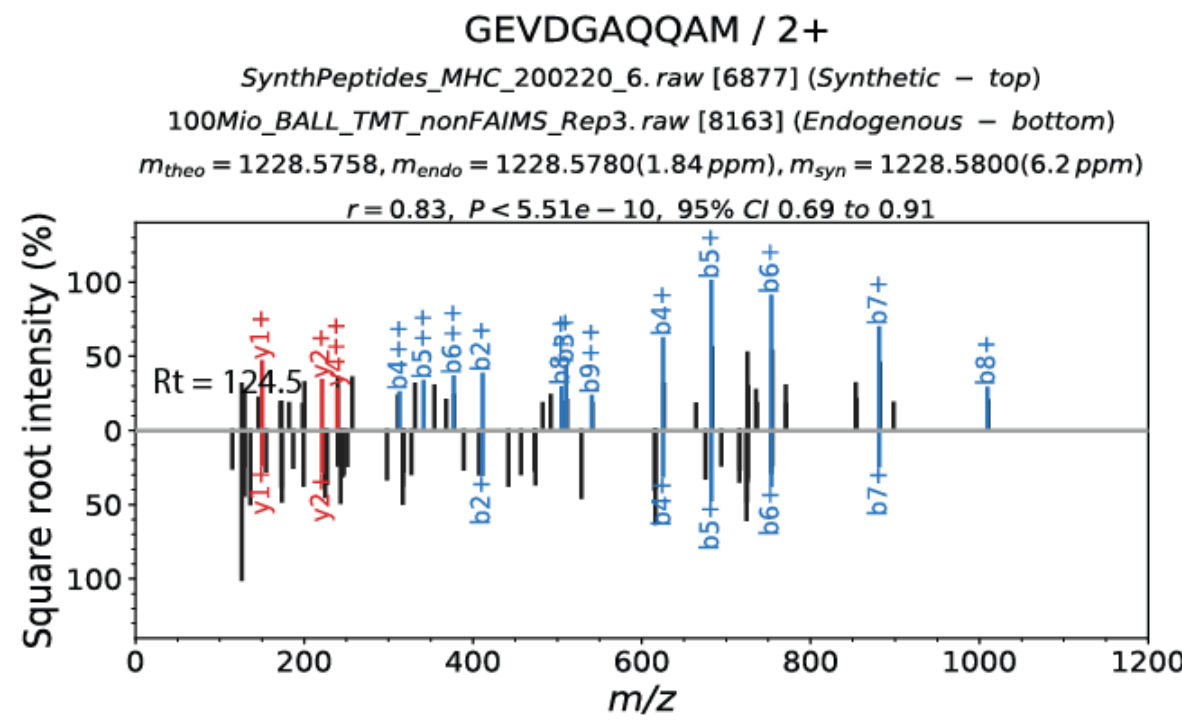

$\mathrm{Rt}=42.0$

$\mathrm{Rt}=44.2$

GLATAVWLL / $2+$

SynthPeptides_MHC_020320_1.raw [23016] (Synthetic - top)

100Mio_BALL_TMT_nonFAIMS_Rep3.raw [35794] (Endogenous - bottom)

$m_{\text {theo }}=1166.7062, m_{\text {endo }}=1166.7074(1.03 p p m), m_{\text {syn }}=1166.7124(5.3 p p m)$

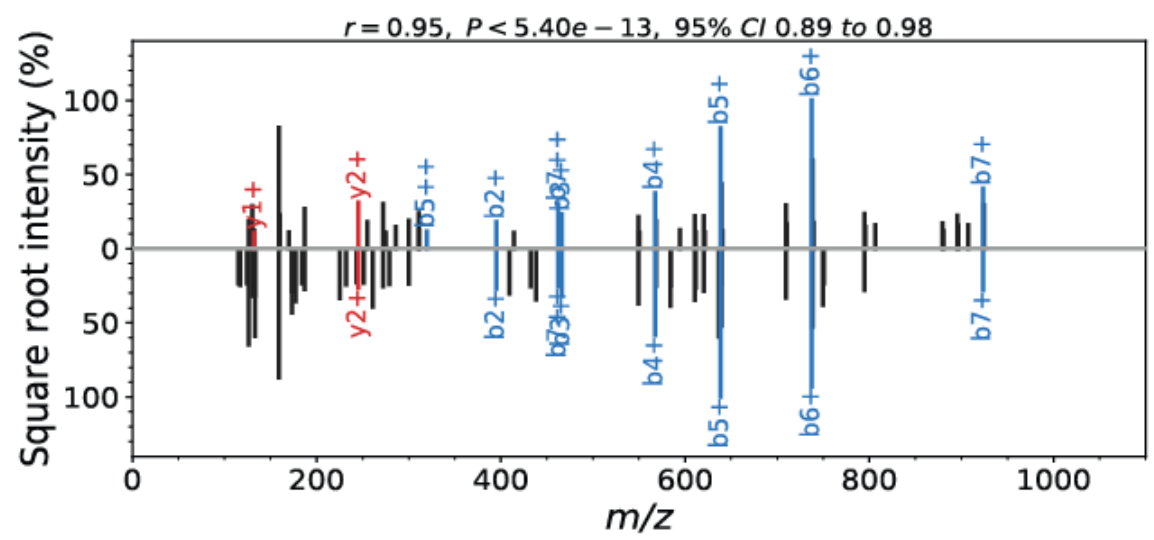

$\mathrm{Rt}=131.2$

$\mathrm{Rt}=130.8$

GTLCLLTFI / $2+$

SynthPeptides_MHC_200220_6.raw [25127] (Synthetic - top) 100Mio_BALL_TMT_nonFAIMS_Rep1.raw [35376] (Endogenous - bottom) $m_{\text {theo }}=1203.6936, m_{\text {endo }}=1203.6962(2.16 p p m), m_{\text {syn }}=1203.6916(1.1 p p m)$

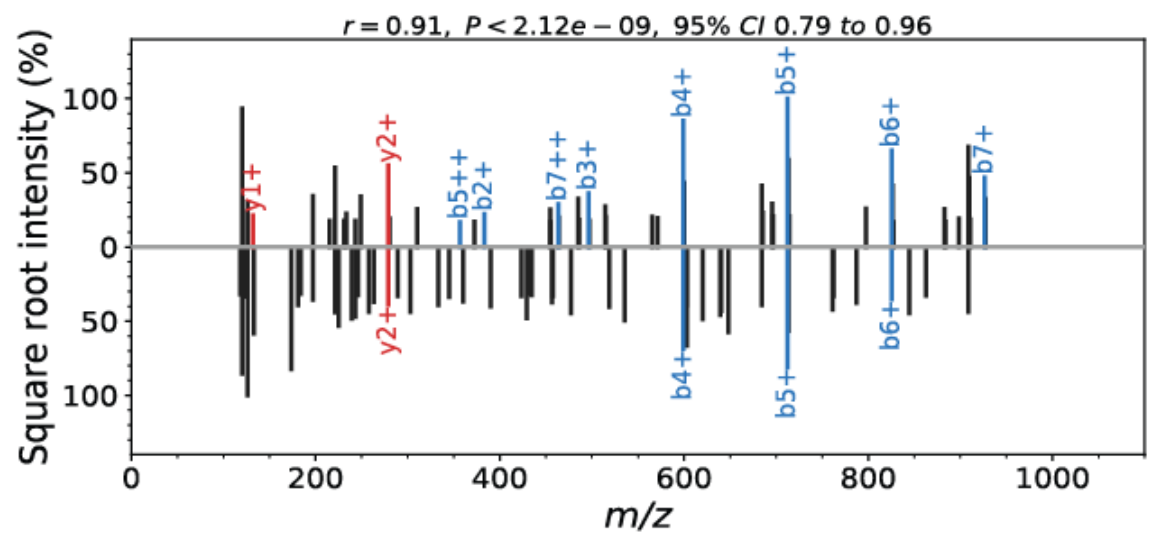

$\mathrm{Rt}=143.2$

$\mathrm{Rt}=130.6$ 
GVANSLLK / $2+$

SynthPeptides_MHC_200220_2.raw [7863] (Synthetic - top)

100Mio_BALL_TMT_nonFAIMS_Rep2.raw [14458] (Endogenous - bottom)

$m_{\text {theo }}=1248.7804, m_{\text {endo }}=1248.7826(1.76 p p m), m_{\text {syn }}=1248.7806(2.9 p p m)$

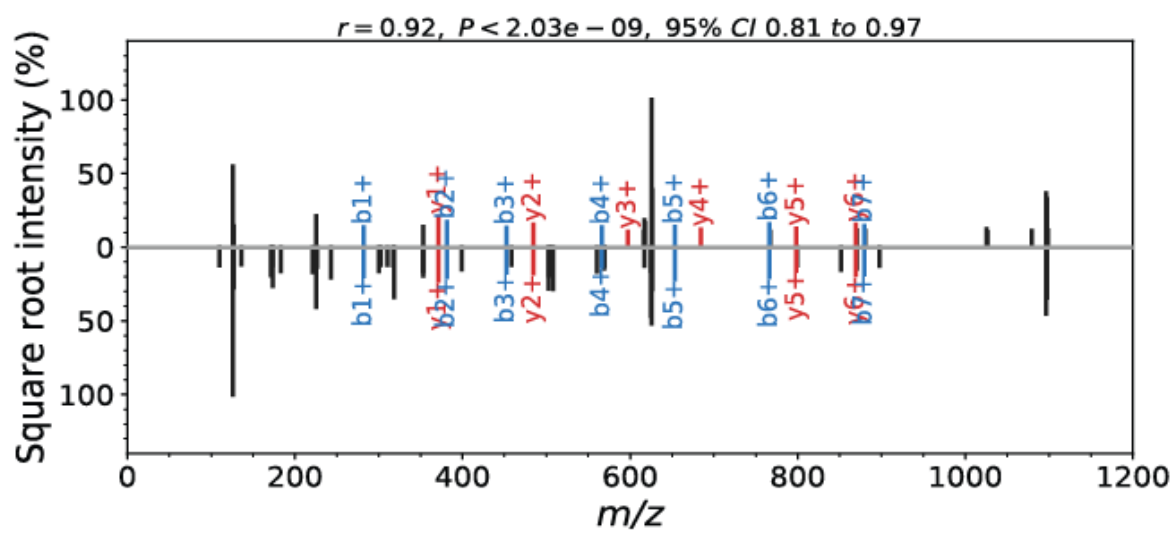

$\mathrm{Rt}=63.9$

$\mathrm{Rt}=65.7$

GVSPVLFLK / $2+$

SynthPeptides_MHC_200220_2.raw [12066] (Synthetic - top) 100Mio_BALL_TMT_nonFAIMS_Rep1.raw [28216] (Endogenous - bottom) $m_{\text {theo }}=1406.8901, m_{\text {endo }}=1406.8934(2.37 \mathrm{ppm}), m_{\text {syn }}=1406.8882(1.5 \mathrm{ppm})$

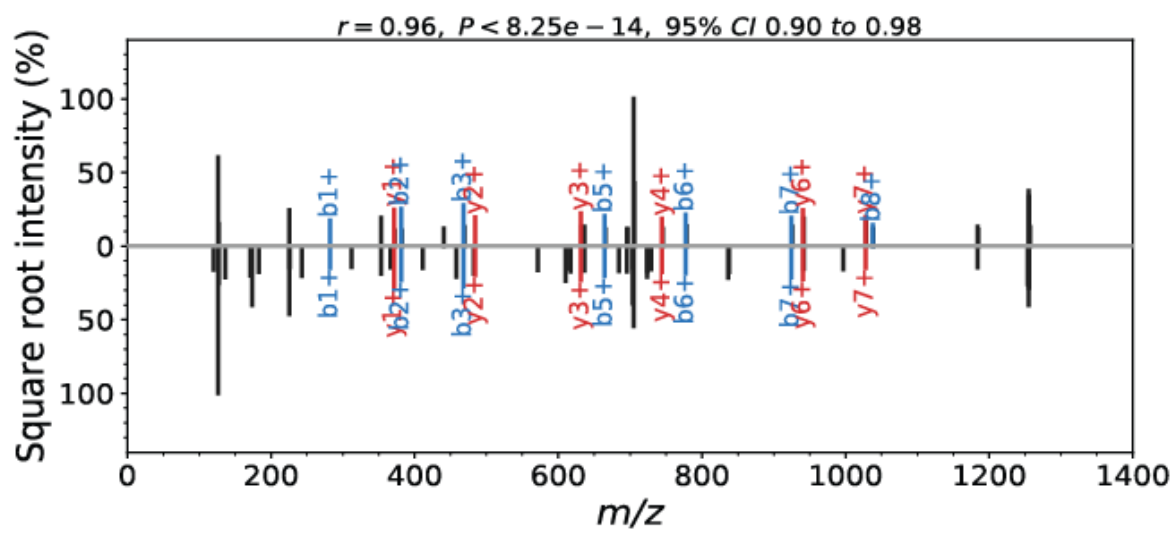

Rt $=101.1$

Rt $=103.8$

IDPFHFLK / $2+$

SynthPeptides_MHC_200220_2.raw [11101] (Synthetic - top) 20Mio_BALL_native_nonFAIMS_Repl.raw [14225] (Endogenous - bottom) $m_{\text {theo }}=1015.5490, m_{\text {endo }}=1015.5440(-4.91 \mathrm{ppm}), m_{\text {syn }}=1015.5456(-0.5 \mathrm{ppm})$

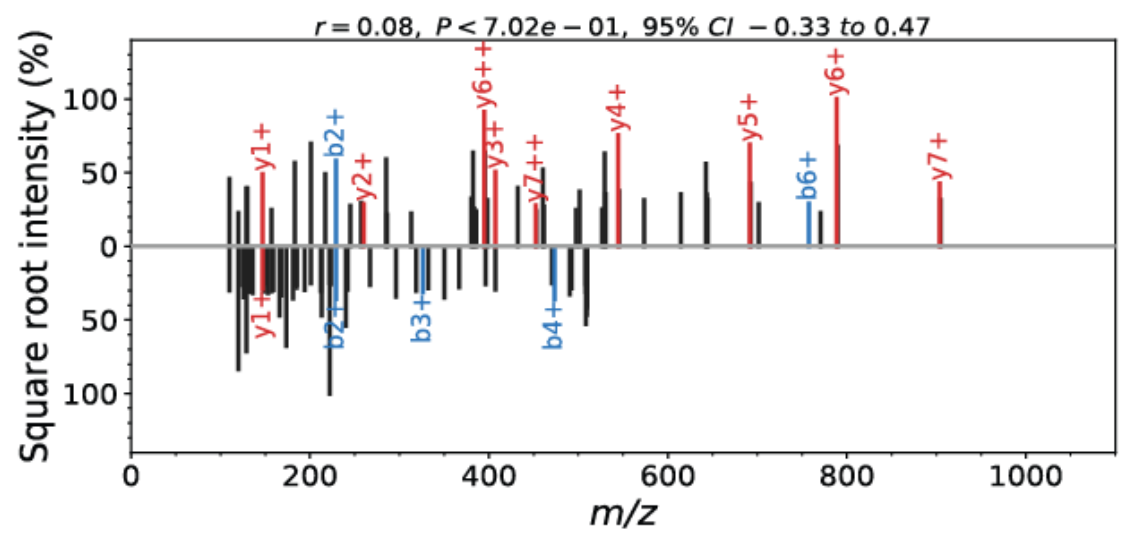

$\mathrm{Rt}=85.2$

$\mathrm{Rt}=86.2$ 
IESEDFGFWSL / 2+

SynthPeptides_MHC_200220_6.raw [24417] (Synthetic - top)

100Mio_BALL_TMT_nonFAIMS_Rep2.raw [34546] (Endogenous - bottom)

$m_{\text {theo }}=1552.7448, m_{\text {endo }}=1552.7480(2.06 p p m), m_{\text {syn }}=1552.7522(7.4 \mathrm{ppm})$

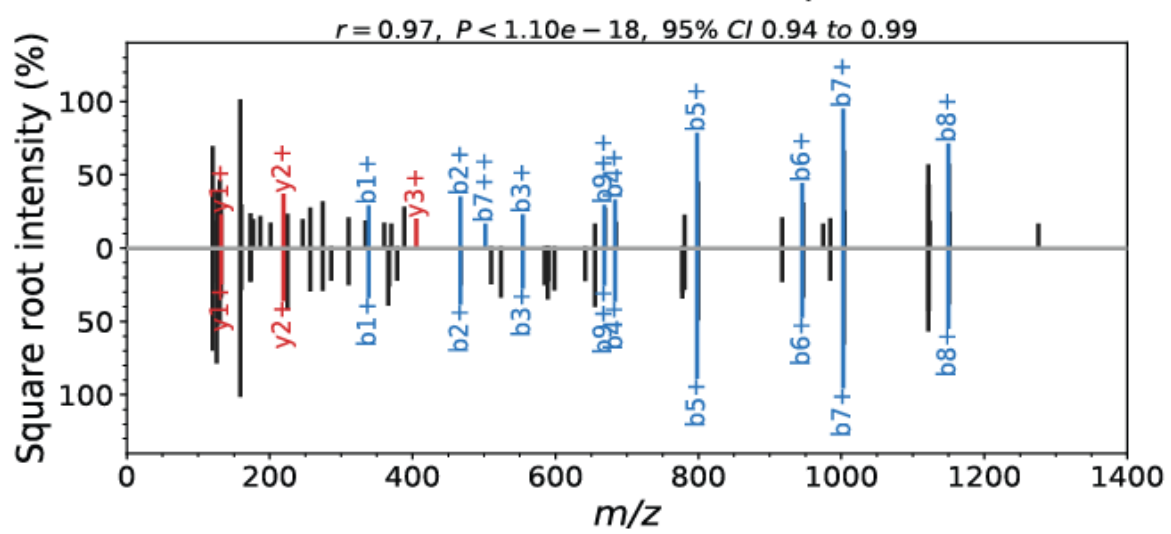

$\mathrm{Rt}=133.5$

$\mathrm{Rt}=133.8$

LENSGFILI / $2+$

SynthPeptides_MHC_020320_1.raw [19319] (Synthetic - top)

100Mio_BALL_TMT_nonFAIMS_Rep3.raw [29002] (Endogenous - bottom)

$m_{\text {theo }}=1452.8590, m_{\text {endo }}=1452.8616(1.79 p p m), m_{\text {syn }}=1452.8632(2.8 p p m)$

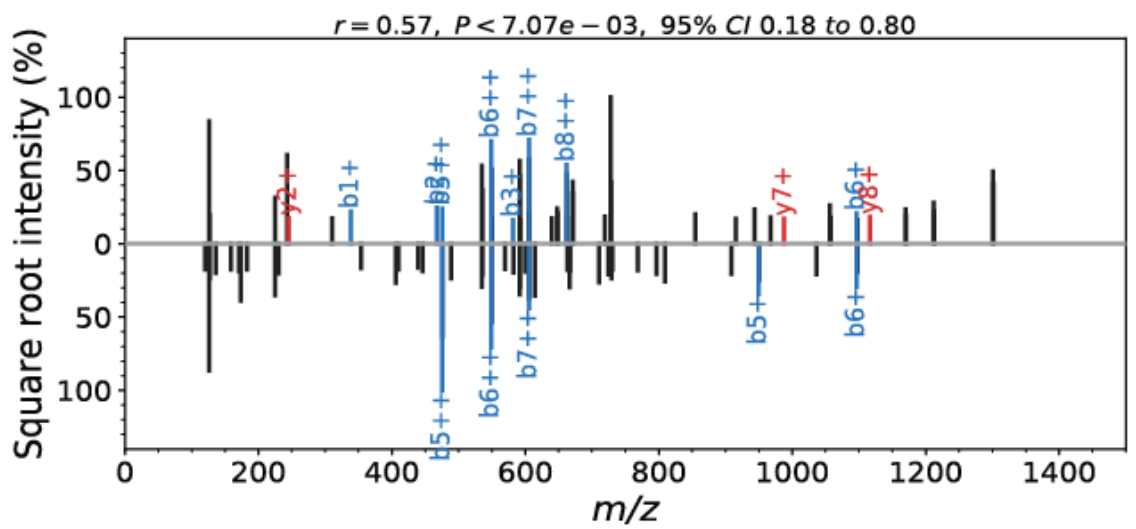

$\mathrm{Rt}=106.2$

$\mathrm{Rt}=107.5$

LLQNLIVLL / $2+$

SynthPeptides_MHC_020320_1.raw [26756] (Synthetic - top) 100Mio_BALL_TMT_nonFAIMS_Rep1.raw [40168] (Endogenous - bottom) $m_{\text {theo }}=1261.8372, m_{\text {endo }}=1261.8412(3.16 p p m), m_{\text {syn }}=1261.8430(4.4 \mathrm{ppm})$

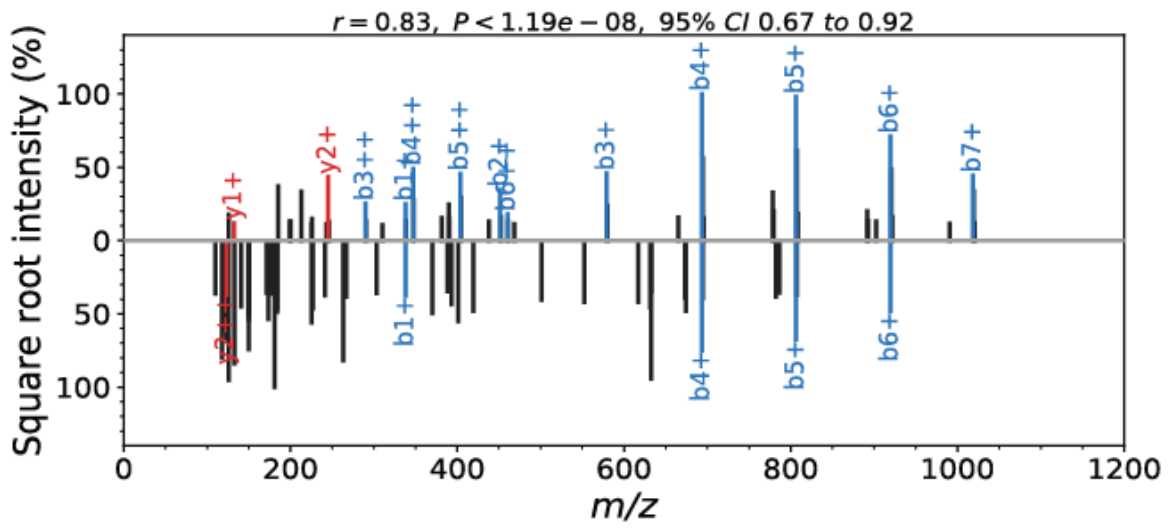

$\mathrm{Rt}=161.3$

$\mathrm{Rt}=161.4$ 
LLSLYLVSI / 2+

SynthPeptides_MHC_200220_6.raw [25179] (Synthetic - top)

100Mio_BALL_TMT_nonFAIMS_Rep3.raw [37373] (Endogenous - bottom)

$m_{\text {theo }}=1243.7791, m_{\text {endo }}=1243.7788(-0.24 p p m), m_{\text {syn }}=1243.7764(0.5 p p m)$

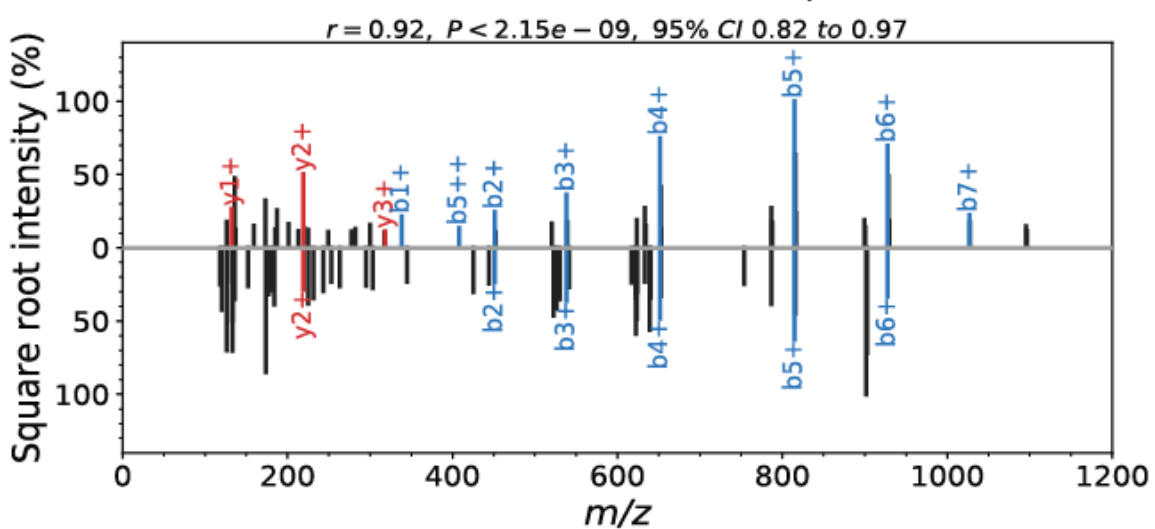

$\mathrm{Rt}=145.0$

$\mathrm{Rt}=143.6$

LSQPLPPGFK / $2+$

SynthPeptides_MHC_200220_5. raw [11071] (Synthetic - top)

100Mio_BALL_native_nonFAIMS_Rep1.raw [12958] (Endogenous - bottom)

$m_{\text {theo }}=1082.6124, m_{\text {endo }}=1082.6146(2.03 \mathrm{ppm}), m_{\text {syn }}=1082.6122(2.6 \mathrm{ppm})$

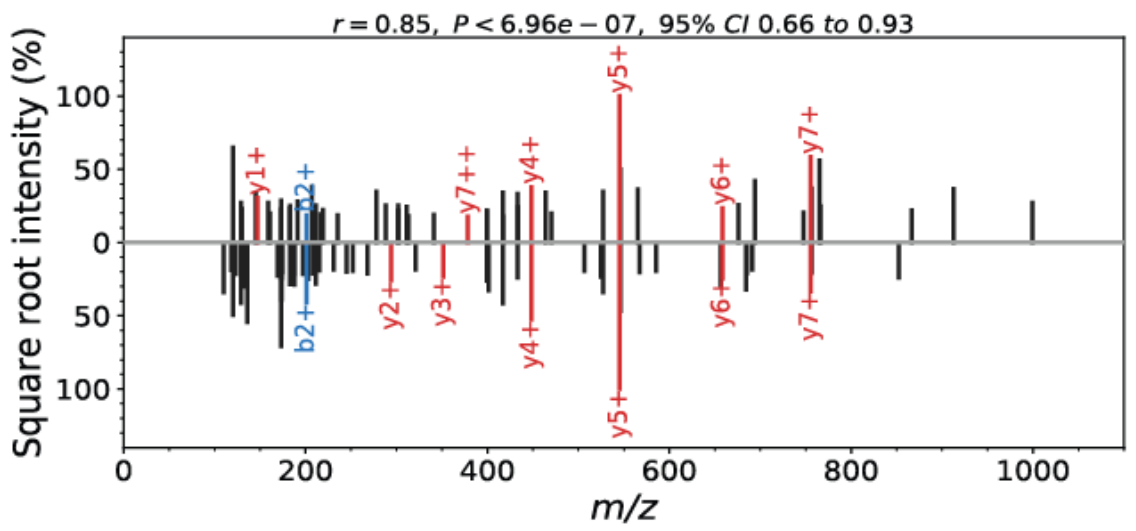

$\mathrm{Rt}=63.6$

$\mathrm{Rt}=66.3$

LSSRLPLGK / 3+

SynthPeptides_MHC_200220_6.raw [12693] (Synthetic - top) 20Mio_BALL_TMT_nonFAIMS_Rep2.raw [10651] (Endogenous - bottom) $m_{\text {theo }}=1417.9022, m_{\text {endo }}=1417.9036(0.99 p p m), m_{\text {syn }}=1417.8976(-0.5 p p m)$

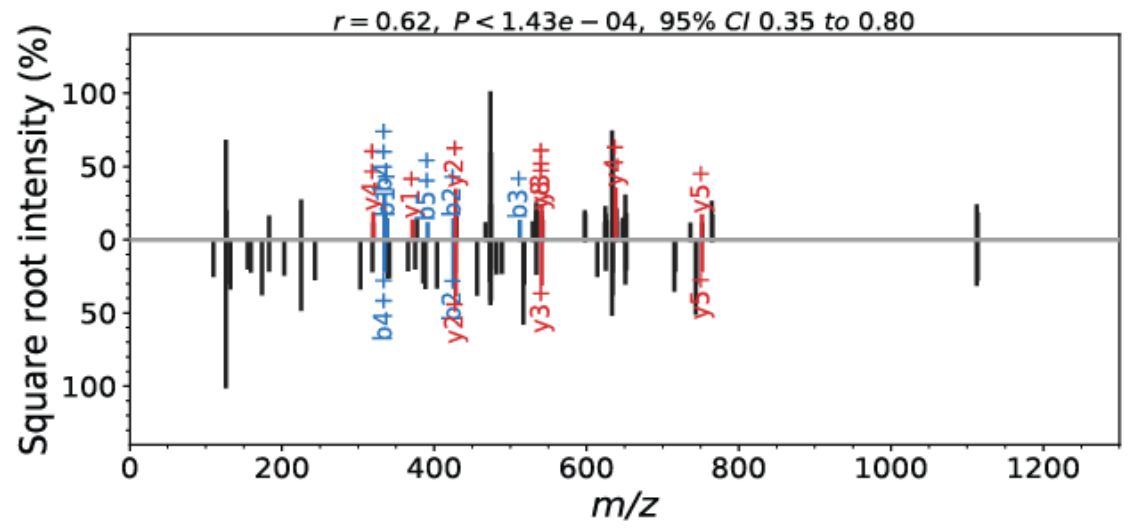

$\mathrm{Rt}=63.2$

$\mathrm{Rt}=63.1$ 
REPLEILITL / 2+

SynthPeptides_MHC_200220_6.raw [21656] (Synthetic - top)

100Mio_BALL_TMT_nonFAIMS_Rep3.raw [34637] (Endogenous - bottom)

$m_{\text {theo }}=1419.8700, m_{\text {endo }}=1419.8714(0.98 p p m), m_{\text {syn }}=1419.8676(1.0 p p m)$

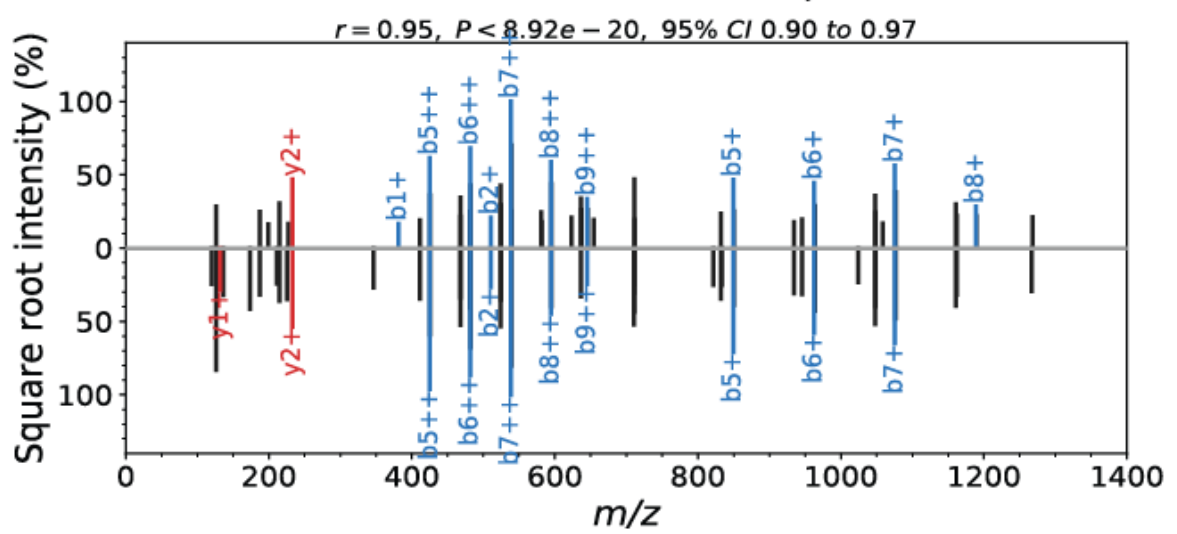

$\mathrm{Rt}=123.0$

$\mathrm{Rt}=125.6$

RIFGFRLWK / 4+

SynthPeptides_MHC_200220_6. raw [16476] (Synthetic - top)

100Mio_BALL_TMT_nonFAIMS_Rep1.raw [27787] (Endogenous - bottom)

$m_{\text {theo }}=1670.0184, m_{\text {endo }}=1670.0213(1.74 \mathrm{ppm}), m_{\text {syn }}=1670.0153(0.9 \mathrm{ppm})$

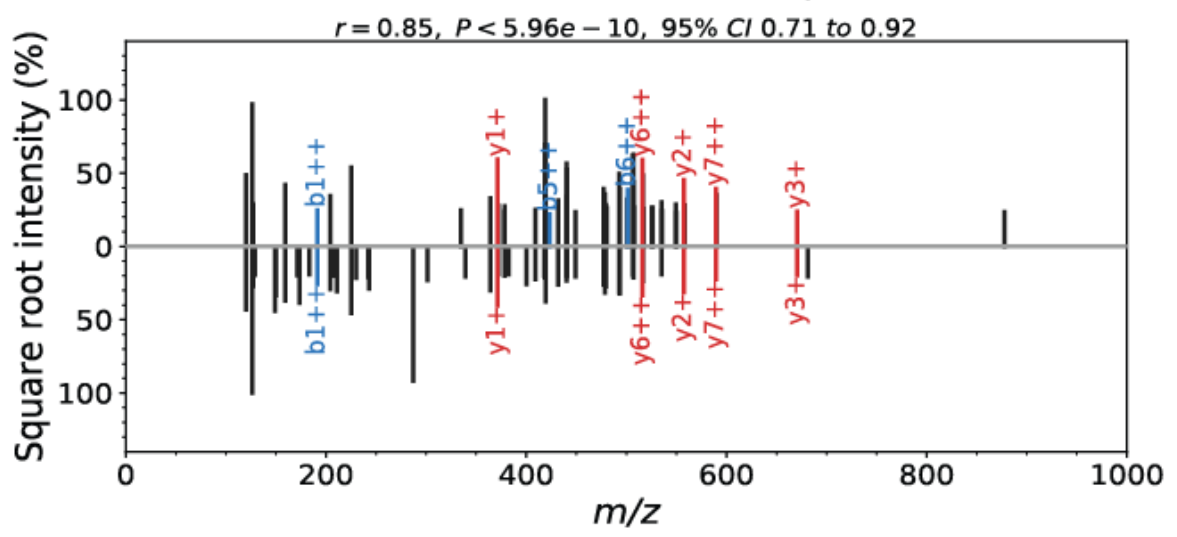

$\mathrm{Rt}=75.3$

$\mathrm{Rt}=72.7$

RLLPLEVLL / $2+$

SynthPeptides_MHC_200220_5.raw [17202] (Synthetic - top) 60Mio_BALL_native_nonFAIMS_Rep1.raw [21715] (Endogenous - bottom) $m_{\text {theo }}=1064.6956, m_{\text {endo }}=1064.6942(-1.31 \mathrm{ppm}), m_{\text {syn }}=1064.6956(2.7 \mathrm{ppm})$

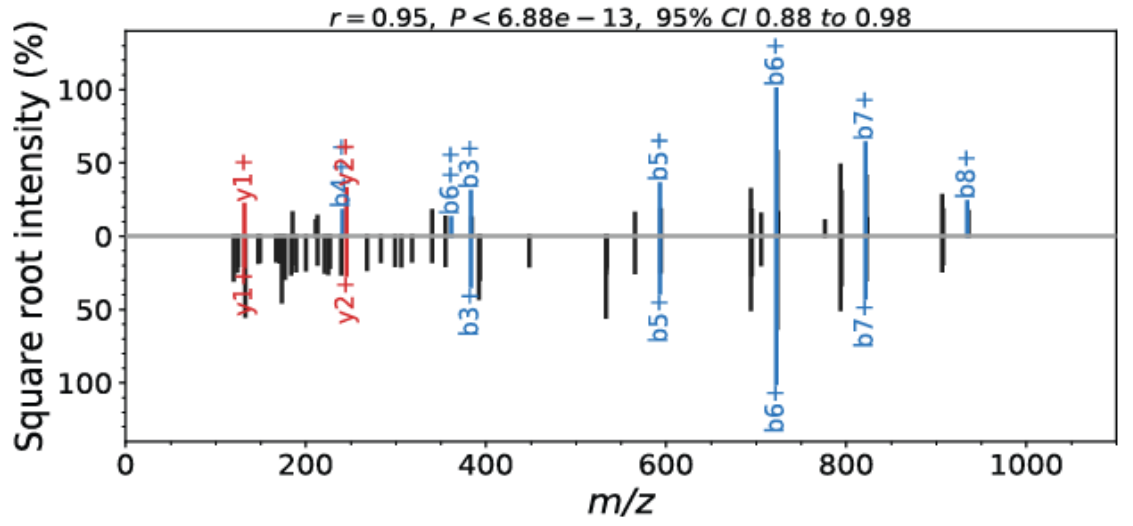

$\mathrm{Rt}=125.2$

$\mathrm{Rt}=125.4$ 
SERDQGTTL / $2+$

SynthPeptides_MHC_200220_3.raw [2972] (Synthetic - top)

100Mio_BALL_native_nonFAIMS_Rep1.raw [3588] (Endogenous - bottom)

$m_{\text {theo }}=1005.4726, m_{\text {endo }}=1005.4764(3.77 p p m), m_{\text {syn }}=1005.4790(9.1 p p m)$

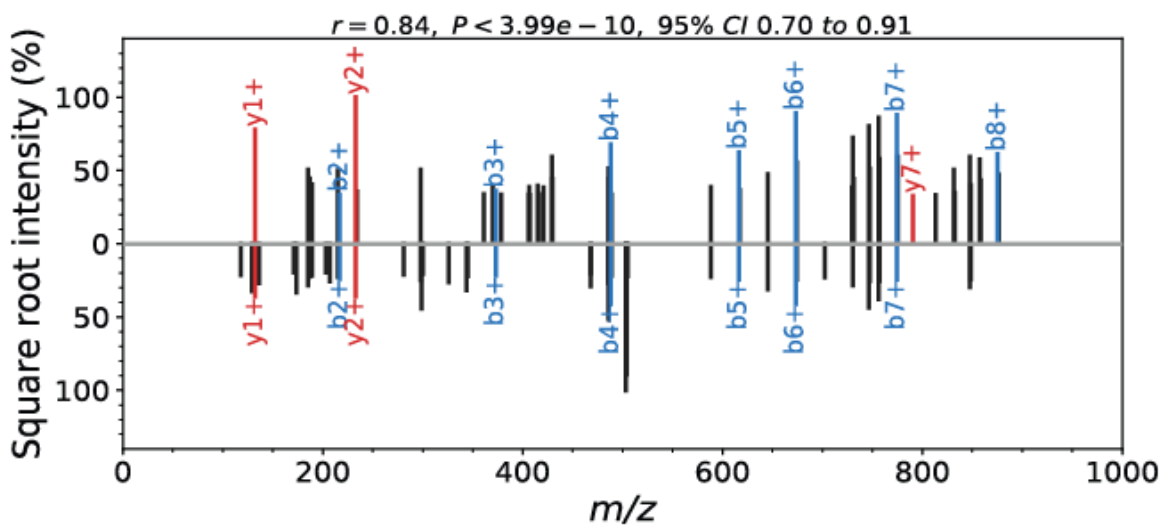

$\mathrm{Rt}=24.9$

$\mathrm{Rt}=25.2$

SLLGIGLLA / 2+

SynthPeptides_MHC_200220_6.raw [21387] (Synthetic - top)

60Mio_BALL_TMT_nonFAIMS_Rep1.raw [28709] (Endogenous - bottom)

$m_{\text {theo }}=1079.6954, m_{\text {endo }}=1079.6966(1.11 \mathrm{ppm}), m_{\text {syn }}=1079.6926(0.2 \mathrm{ppm})$

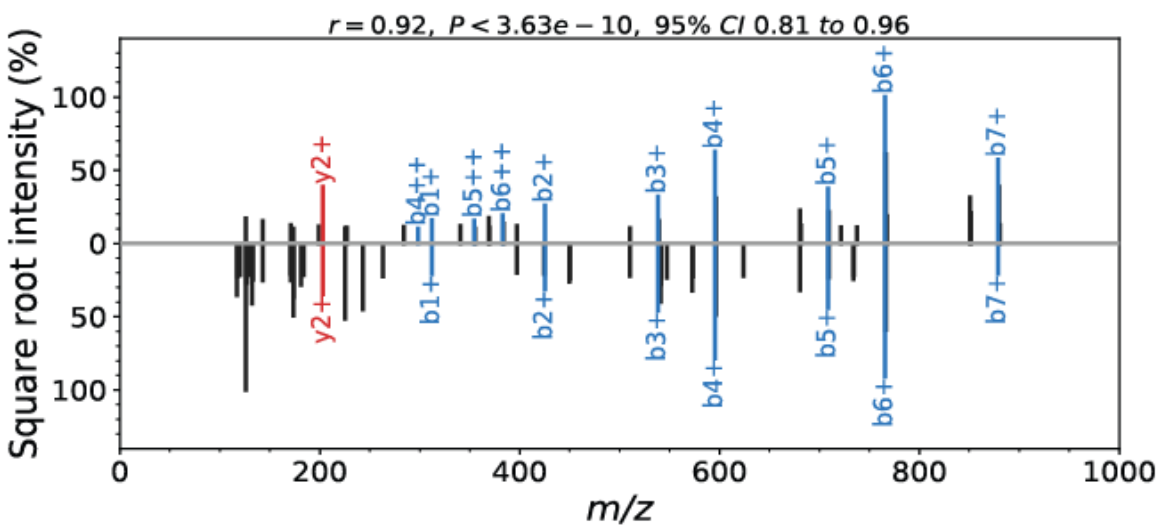

$\mathrm{Rt}=119.2$

$\mathrm{Rt}=120.0$

SLTALVFHV / 2+

SynthPeptides_MHC 200220_5. raw [16037] (Synthetic - top)

20Mio_BALL_TMT_nonFAIMS_Rep3.raw [20058] (Endogenous - bottom)

$m_{\text {theo }}=1209.7121, m_{\text {endo }}=1209.7126(0.43 p p m), m_{\text {syn }}=1209.7136(4.0 p p m)$

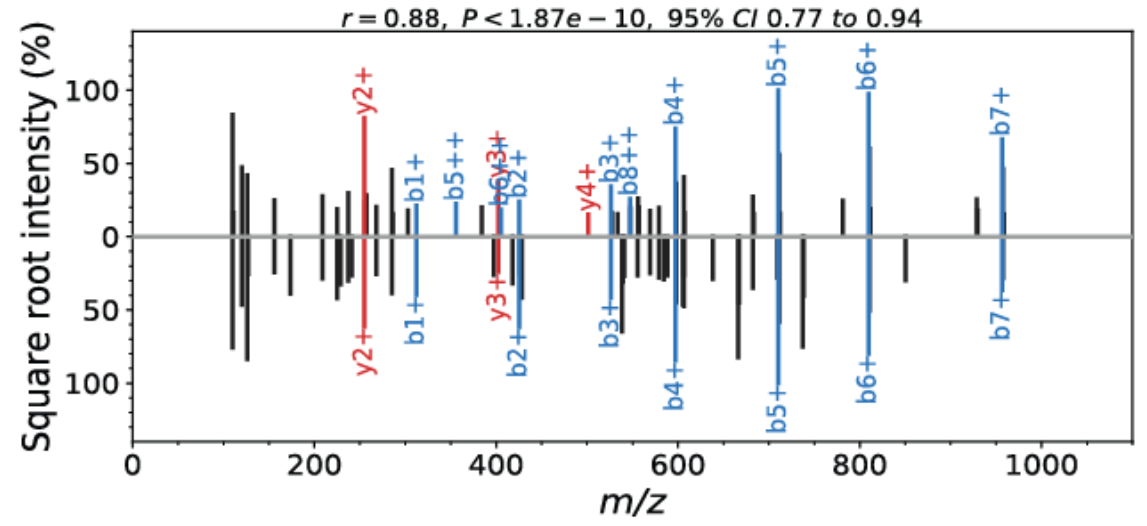

$\mathrm{Rt}=111.6$

$\mathrm{Rt}=111.9$ 
TSFAETWMK / $2+$

SynthPeptides_MHC_200220_6.raw [15755] (Synthetic - top) 60Mio_BALL_TMT_nonFAIMS_Rep2.raw [20678] (Endogenous - bottom) $m_{\text {theo }}=1547.8058, m_{\text {endo }}=1547.8070(0.83 p p m), m_{\text {syn }}=1547.8028(0.8 p p m)$

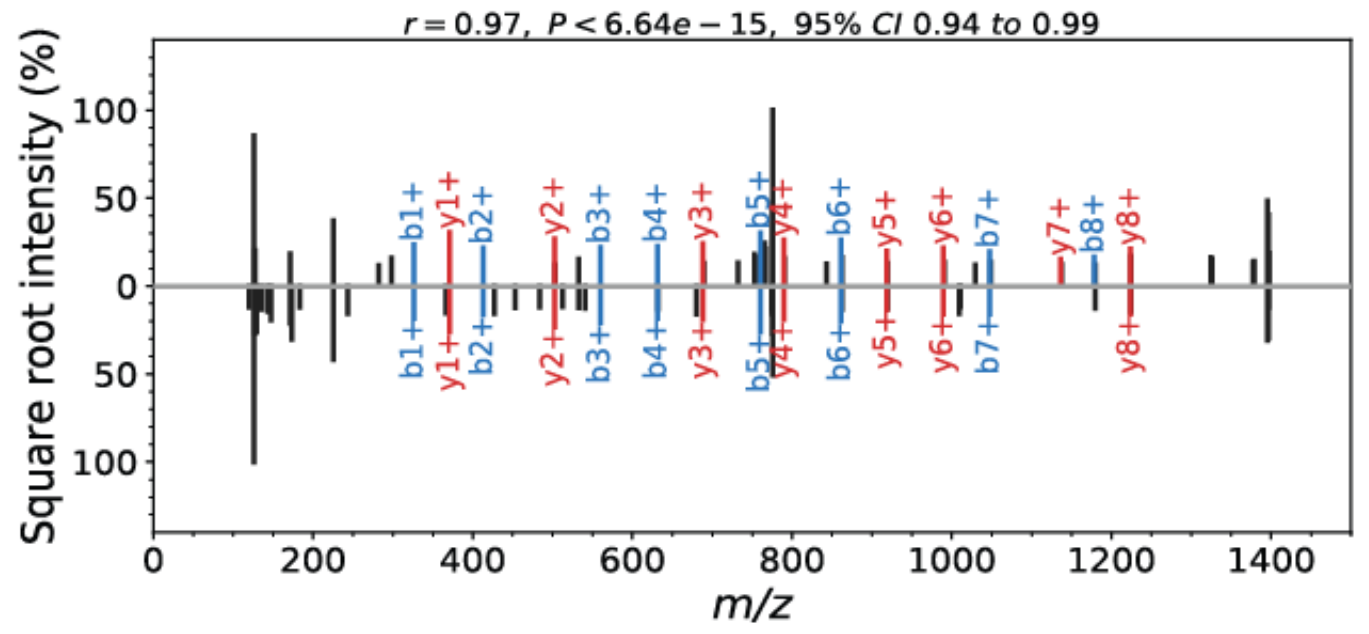

$\mathrm{Rt}=94.4$

$\mathrm{Rt}=91.1$ 